See Article page 1604

\section{Commentary: Mitigating cardiac surgical operative risk for the most vulnerable}

\author{
Roosevelt Bryant III, MD
}

As the body of literature continues to grow regarding racial disparities in congenital heart surgery outcomes, it is challenging to find a common thread that explains either the cause of the inequality or how providers are responding to it. Most studies end up raising more questions than providing understanding. It has been shown, for example, that African American infants have an approximately 2-fold increased risk of in-hospital mortality after correction of congenital heart defects. ${ }^{1}$ Despite a lack of uniform agreement, we are gradually beginning to see literature emerge that provides clarity. Tjoeng and colleagues ${ }^{2}$ demonstrated that the higher postoperative mortality (40\% higher than in White patients) seen in African American children undergoing cardiac surgery was mediated by worse severity of illness on admission to the hospital. They hypothesized this may be the result of unequal access to care such as subspecialty services and perhaps a delay in diagnosis.

We are also gaining insight into how providers are attempting to mitigate operative risk in vulnerable patients by clinical pathway development. This is evident in the study by Spigel and colleagues ${ }^{3}$ in this issue of the Journal. The authors used the Area Deprivation Index (ADI) to assess the impact of socioeconomic position on length of stay after the Norwood procedure. The ADI incorporates data on income, housing, education, and employment when constructing a neighborhood

\footnotetext{
From the Division of Congenital Heart Surgery, The Heart Center, Phoenix Children's Hospital, Phoenix, Ariz.

Disclosures: The author reported no conflicts of interest.

The Journal policy requires editors and reviewers to disclose conflicts of interest and to decline handling or reviewing manuscripts for which they may have a conflict of interest. The editors and reviewers of this article have no conflicts of interest.

Received for publication Nov 3, 2021; revisions received Nov 3, 2021; accepted for publication Nov 3, 2021; available ahead of print Nov 8, 2021.

Address for reprints: Roosevelt Bryant III, MD, The University of Arizona College of

Medicine, Cardiovascular Surgery, 1919 E Thomas Rd, Phoenix, AZ 85253

(E-mail: rbryant1@phoenixchildrens.com).

J Thorac Cardiovasc Surg 2022;163:1615-6

$0022-5223 / \$ 36.00$

Copyright (C) 2021 by The American Association for Thoracic Surgery

https://doi.org/10.1016/j.jtcvs.2021.11.004
}

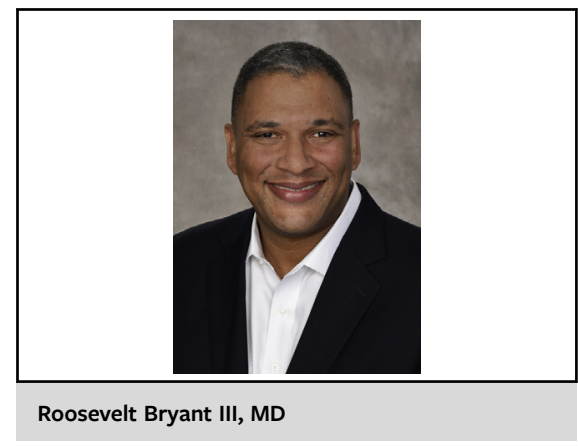

CENTRAL MESSAGE

Pediatric Heart Centers are

developing care pathways to

mitigate operative risk in vulner-

able patient populations.

socioeconomic profile. It is a more complete picture than income alone. They found a $4 \%$ increase in length of stay for every $10 \%$ increase in the ADI. For populations with limited resources and access to care, these findings suggest centers are keeping patients in the hospital to mitigate risk. ${ }^{3}$ But do we know if this strategy is achieving its intended purpose? There are data to suggest this may be the case. Karamlou and colleagues ${ }^{4}$ used the Pediatric Health Information System database to assess the relationship between socioeconomic and racial disparities on the outcome of congenital heart disease interventions. The authors went one step further and looked at the interactions among factors that might mitigate postoperative risk. Although Black race was associated with higher overall mortality, that risk was mitigated in Black neonates by a significantly longer length of hospital stay. Black neonates also had a higher prevalence of noncardiac procedures such as feeding tubes and Nissen fundoplication. ${ }^{4}$ With these data we are beginning to see the impact of clinical pathway development designed to improve outcomes for vulnerable patients. Spigel and colleagues $^{3}$ made a valid argument that length of stay, as a quality metric, should not be used to punish centers that care for at-risk patients. In the bigger picture, their data, along with other emerging literature, demonstrate that clinicians are responding to the needs of at-risk patients. It gives us hope that one day racial and socioeconomic disparities in medicine and society as a whole will be things of the past. 


\section{References}

1. Dibardino DJ, Pasquali SK, Hirsch JC, Benjamin DK, Kleeman KC, Salazar JD, et al. Effect of sex and race on outcome in patients undergoing congenital heart surgery: an analysis of the Society of Thoracic Surgeons Congenital Heart Surgery Database. Ann Thorac Surg. 2012;94:2-10.

2. Tjoeng YL, Jenkins K, Deen JF, Chan T. Association between race/ethnicity, illness severity, and mortality in children undergoing cardiac surgery. J Thorac Cardiovasc Surg. 2020;160:1570-9.
3. Spigel ZA, Kalustian AB, Zink JA, Binsalamah ZM, Caldarone CA. Low parental socioeconomic position results in longer post-Norwood length of stay. J Thorac Cardiovasc Surg. 2022;163:1604-11.e1.

4. Karamlou T, Hawke JL, Zafar F, Kafle M, Tweddell JS, Najm HK, et al. Widening our focus: characterizing socioeconomic and racial disparities in congenital heart disease. Ann Thorac Surg. Apr 16, 2021; https://doi.org/10.1016/j.athorac sur.2021.04.008
See Article page 1604 .

\section{Commentary: Length of stay as measure of quality: A misty strategy that might backfire}

\author{
Deborah Kozik, DO, and Bahaaldin Alsoufi, MD
}

What defines quality in surgery? The most widely used outcome metric is mortality, which is clearly important, but is also one dimensional and does not address longterm results, including functional status and quality of life. In an effort to define more comprehensive measures of outcomes, a working group that is developing a composite quality metric for congenital heart surgery proposed including hospital length of stay (LOS) in the morbidity domain for quality. ${ }^{1}$ In view of this proposal, Spigel and colleagues ${ }^{2}$ chose to look specifically at the influence of parental socioeconomic status (SES) on LOS following the Norwood operation. ${ }^{2}$ The authors examined hospital LOS in all Norwood hospital survivors who were discharged home between 2008 and 2018. They developed 37 measurable variables that influenced postoperative LOS, including socioeconomic factors, intraoperative factors, and postoperative factors. Utilizing the Area Deprivation Index as a measure of SES (a higher

From the Department of Cardiovascular and Thoracic Surgery, University of Louisville School of Medicine, Norton Children's Hospital, Louisville, Ky.

Disclosures: The authors reported no conflicts of interest.

The Journal policy requires editors and reviewers to disclose conflicts of interest and to decline handling or reviewing manuscripts for which they may have a conflict of interest. The editors and reviewers of this article have no conflicts of interest.

Received for publication Nov 24, 2021; revisions received Nov 24, 2021; accepted for publication Nov 30, 2021; available ahead of print Dec 3, 2021.

Address for reprints: Bahaaldin Alsoufi, MD, Department of Cardiovascular and Thoracic Surgery, University of Louisville School of Medicine, Norton Children's Hospital, 201 Abraham Flexner Way, Suite 1200, Louisville, KY 40202 (E-mail: balsoufi@hotmail.com).

J Thorac Cardiovasc Surg 2022;163:1616-7

$0022-5223 / \$ 36.00$

Copyright (c) 2021 by The American Association for Thoracic Surgery

https://doi.org/10.1016/j.jtcvs.2021.11.065

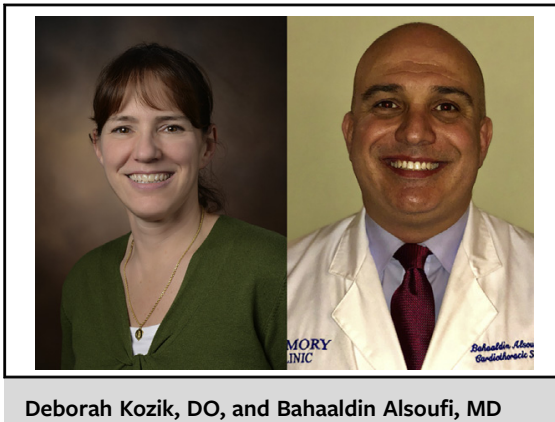

Deborah Kozik, DO, and Bahaaldin Alsoufi, MD

CENTRAL MESSAGE

The association of hospital

length of stay and many

nonclinical patient and socio-

economic factors limits its utility

as a measure of quality.

number correlates with a lower SES), they demonstrated a $4 \%$ increase in LOS for every $10 \%$ increase in Area Deprivation Index, suggesting a significant relationship between SES and LOS.

The authors' findings are in line with other reports that demonstrated an association between SES and various outcomes in pediatric cardiac surgery. Utilizing Single Ventricle Reconstruction Trial data, an evaluation of SES and outcomes following the Norwood procedure found a linear relationship between SES and 1-year mortality or transplant with the lowest rate of mortality or transplantation observed in patients with the highest SES. ${ }^{3}$ A systematic review of the social determinants of health and outcomes for children and adults with congenital heart disease found that poverty and low SES were consistently associated with adverse postoperative outcomes, including unplanned readmission, longer LOS, higher resource utilization, and lower school functioning. ${ }^{4}$ The correlation between SES and LOS is also not isolated to congenital heart surgery. Multiple studies 